\title{
Pengembangan Budaya Sekolah Berprestasi: Penanaman Nilai Etos Berprestasi
}

\author{
Ageng Pratiwi ${ }^{1}$, Erny Roesminingsih , Karwanto ${ }^{3}$ \\ ${ }^{123}$ Surabaya State University \\ Email: ageng.19012@mhs.unesa.ac.id
}

\begin{abstract}
Senior High School Muhammdiyah 10 Surabaya is a school that dares to make a different curriculum from Diknas. It was rejected because it did not fit the existing curriculum. In its first year, the school receives two classes of students. This achievement soared in the second year. Second year there are five classes. The curriculum used at Senior High School Muhammadiyah 10 Surabaya is called "Talent Executive School." This study aims to find out the development of outstanding school culture at Senior High School Muhammadiyah 10 Surabaya, also describe the form of outstanding school culture, the process of planting values and ethos of achievement to students and knowing the implications of the development of outstanding school culture at Senior High School Muhammadiyah 10 Surabaya. Although the facilities and infrastructure at Senior High School Muhammadiyah 10 Surabaya have limitations but they are able to continue to develop the potential and ethos of interpreting in the academic and non-academic fields. So it becomes an attraction for researchers to conduct a researcher in the school with a different school style than usual. This study uses a qualitative descriptive approach. Data collection using observation techniques, interviews and documentation. The planting of values and ethos of achievement in students is carried out through school orientation activities, learning process, learning evaluation, extracurricular, achievement awards, love for alma mater, teacher conscientiousness, cooperation with parents of students and planting an outstanding culture. The results showed that the school culture developed at Senior High School Muhammadiyah 10 Surabaya is through educational programs and potential interests including archery, futsal, athletics, pencak silat, archery, music, hockey, dance and others.
\end{abstract}

Keywords: Value Planting, Ethos Of Achievement And School Culture

Abstrak. SMA Muhammdiyah 10 Surabaya ini adalah sekolah yang berani membuat kurikulum berbeda dari Diknas. Sempat ditolak karena tidak sesuai dengan kurikulum yang ada. Di tahun pertama, sekolah menerima dua kelas siswa. Pencapaian ini melejit di tahun kedua. Tahun kedua ada lima kelas. Kurikulum yang dipakai di SMA Muhammadiyah 10 Surabaya ini bernama "Talent Executive School." Penelitian ini memiliki tujuan untuk mengetahui pengembangan budaya sekolah berprestasi di SMA Muhammadiyah 10 Surabaya, juga mendeskripsikan bentuk budaya sekolah berprestasi, proses penanaman nilai dan etos berprestasi kepada peserta didik dan mengetahui implikasi dari pengembangan budaya sekolah berprestasi di SMA Muhammadiyah 10 Surabaya. Walaupun sarana dan prasarana di SMA Muhammadiyah 10 Surabaya memiliki keterbatasan tetapi mereka mampu terus mengembangkan potensi dan etos berpretasi di bidang akademik maupun non akademik. Sehingga menjadi daya tarik peneliti untuk melakukan sebuah peneliti di sekolah tersebut dengan gaya sekolah yang berbeda dari pada umumnya. Penelitian ini menggunakan pendekatan deskriptif kualitatif. Pengumpulan data menggunakan teknik observasi, wawancara dan dokumentasi. Penanaman nilai dan etos berprestasi pada peserta didik dilakukan melalui kegiatan orientasi sekolah, proses pembelajaran, evaluasi belajar, ekstrakurikuler, penghargaan prestasi, kecintaan terhadap almamater, keteladanan guru, kerjasama dengan orangtua peserta didik dan penanaman budaya berprestasi. Hasil penelitian menunjukkan bahwa budaya sekolah yang dikembangkan di SMA Muhammadiyah 10 Surabaya adalah melalui Program pendidikan dan potensi minat meliputi keberbakatan, futsal, atletik, pencak silat, panahan, musik, hockey, tari dan lainnya.

Kata Kunci: Penanaman Nilai, Etos Berprestasi Dan Budaya Sekolah.

\section{PENDAHULUAN}

Budaya sekolah merupakan ciri khas, karakter atau watak, dan citra sekolah tersebut di masyarakat luas. Penerapan kultur sekolah yang tepat akan mempunyai pengaruh yang berarti dalam aktivitas belajar siswa, maupun dalam mempengaruhi guru untuk melakukan pekerjaan yang lebih efisien dan efektif untuk mencapai 
kinerja guru yang baik (Bukhori dan Anita, 2009). Budaya sekolah akan mempengaruhi suasana kelas, baik kebebasan yang dinikmati peserta didik dalam mengembangkan pikiran dan prestasinya ataupun sebaliknya bisa menjadi pengekangan dan keterbatasan tehadap pengembangan peserta didik dan sekolah itu sendiri. Penanaman nilai-nilai budaya sekolah dilaksanakan terutama saat pembelajaran di kelas dan akan berlanjut dalam pola kelakuan dan interaksi di luar kelas. Peserta didik pada saat pertama memasuki lingkungan sekolah akan mengalami proses sosialisasi dimana peserta didik memahami dan menjalankan budaya sekolah. Proses pembelajaran peserta didik dapat berjalan lancar karena ada budaya sekolah yang menentukan kelakuan dan tujuan yang diharapkan oleh guru, peserta didik dan para stakeholder. Nilai-nilai dan norma yang berlangsung di dalam sekolah juga harus memperhatikan budaya masyarakat terutama yang berlaku dalam keluarga peserta didik.

Sekolah menjadi tempat disematkan harapan bagi anak-anak. Karena secara sosial, ia menjadi tempat pertama dimana seorang anak pertama kali bersosialisasi dan bergaul dengan anak-anak sebaya yang memiliki perbedaan dan keunikan masing-masing. Sesuai dengan prinsip individu-kemanusiaan, bahwa setiap orang adalah unik, baik itu karena latar belakang ekonomi, sosial dan budaya keluarga, dan agama, bahkan karena akar biologis yang diturunkan oleh orang tuanya. Keunikan setiap anak tersebut terekspresi sedemikian rupa yang kemudian melahirkan berbagai pesona perbedaan di lingkungan sekolah. Perbedaan tersebut dapat menjadi pemicu pertentangan yang kemudian terekspresi menjadi perilaku bully dan kekerasan, atau dapat menjadi pemicu bagi persahabatan dan bertemanan. Kedua bentuk perilaku tersebut memiliki peluang kejadian yang sama, tergantung pada dasardasar nilai, budaya, dan iklim sekolah yang diciptakan oleh komunitas dan civitas akademika di sekolah tersebut.

Guru sebagai tuan (rumah) di sekolah yang bertugas mengelolah nilai-nilai kebudayaan dan iklim sekolah baik melalui pembelajaran di kelas ataupun pembelajaran di luar kelas, memiliki peran utama untuk mengarahkan perilaku anak sekolah lebih cenderung meresapi dan mengamalkan budaya damai, persahabatan dan pertemanan dalam merespon perbedaan yang ada di antara siswa. Iklim sekolah yang dibentuk oleh faktor-faktor seperti: norma dan aturan sekolah, bentuk hubungan antar aktor seperti siswa, guru, staf dan pimpinan sekolah, serta relasi dengan aktor-aktor dan faktor di luar sekolah, sangat berpengaruh terhadap prestasi dan sikap siswa, bahkan terhadap sikap dan motivasi guru dalam mengajar. Banyak laporan riset baik berbentuk skripsi, ataupun disertasi yang menerangkan hubungan antara persepsi anak terhadap iklim sekolah dengan motivasi belajar atau terhadap prestasi belajar.

Budaya Guru di SMA Muhammadiyah 10 Surabaya selain menjalankan kode etik juga harus memiliki tanggung jawab atas amanah yang diberikan, kreatif dan inovatif, religius, menjadi pribadi yang dekat dengan siswa. Sehingga disini terjalin komunikasi yang baik antar siswa dan guru dan menumbuhkan budaya berprestasi yang tinggi. Di sekolah menyediakan dan memberikan fasilitas yang di minati siswa dengan mendatangkan guru-guru dibidang ahlinya sehingga pesertadidik dengan nyaman mengembangkan potensi berprestasi nya dengan tetap menekankan nilai-nilai yang baik.

Budaya sekolah dibangun dalam proses yang lama seiring perkembangan sekolah dan selalu beradaptasi mengikuti perubahan sosial. Penelitian budaya sekolah ternyata masih kurang dan selama ini penelitian pendidikan lebih banyak hanya berfokus di dalam ruang kelas seperti didaktik dan metodik. Padahal penelitian budaya sekolah telah banyak dilakukan di negara maju dan memberikan kontribusi yang positif terhadap peningkatan prestasi peserta didik. Berlatar belakang diatas, penelitian ini bertujuan untuk mendeskripsikan bentuk budaya sekolah, proses penanaman nilai dan etos berprestasi kepada peserta dan mengetahui pengembangan budaya sekolah berprestasi di SMA Muhammadiyah 10 Surabaya. 


\section{METODE PENELITIAN}

Penelitian ini merupakan penelitian deskriptif kualitatif yang bertujuan untuk mengemukakan gejala-gejala secara lengkap serta hubungannya satu sama lain di dalam aspekaspek yang diselidiki. Lokasi dalam penelitian ini adalah SMA Muhammadiyah 10 Surabaya . Fokus penelitian dirinci dalam tiga masalah yaitu: budaya sekolah yang dimiliki SMA Muhammadiyah 10 Surabaya, proses penanaman nilai dan etos berprestasi kepada peserta didik SMA Muhammadiyah 10 Surabaya, dan implikasi pengembangan budaya sekolah berprestasi di SMA Muhammadiyah 10 Surabaya.

Penelitian ini menggunakan sumber data berupa data primer dan data sekunder. Data primer diperoleh dari subyek penelitian yakni guru dan peserta didik di SMA Muhammadiyah 10 Surabaya Intensitas yang rutin antara guru dan peserta dan kontak langsung dalam pembelajaran di dalam kelas maupun diluar kelas dapat menjelaskan tentang budaya sekolah berprestasi di SMA Muhammadiyah 10 Surabaya. Data primer yakni guru dan peserta didik tersebut diambil sampel (tidak seluruh guru dan peserta didik) dengan pertimbangan tertentu. Data sekunder didapatkan dari literatur-literatur relevan yang mendukung data penelitian yang diantaranya adalah data sekolah, tata tertib sekolah, rekap data prestasi peserta didik dari tahun 2014-2019, data ekstrakurikuler Majalah SMAMX Surabaya. Pengumpulan data dilakukan dengan teknik observasi, wawancara dan dokumentasi. Pelaksanaan observasi di lingkungan SMA Muhammadiyah 10 Surabaya dilakukan dengan prosedur ketat yang berlaku di sekolah tersebut. Observasi dilakukan tanpa mengganggu kegiatan pembelajaran. Observasi ditekankan pada fokus-fokus yang berkatan dengan rumusan masalah, yakni meliputi: lingkungan dan prasarana fisik sekolah, simbolsimbol yang berisi pesan-pesan positif berupa tulisan, gambar atau monument yang ada di lingkungan sekolah serta interaksi dan perilaku warga sekolah terutama para significant other dan peserta didik.

\section{HASIL PENELITIAN DAN PEMBAHASAN}

Budaya sekolah merupakan ciri khas, karakter atau watak, dan citra sekolah tersebut di masyarakat luas. Penerapan kultur sekolah yang tepat akan mempunyai pengaruh yang berarti dalam aktivitas belajar siswa, maupun dalam mempengaruhi guru untuk melakukan pekerjaan yang lebih efisien dan efektif untuk mencapai kinerja guru yang baik (Bukhori dan Anita, 2009). Budaya sekolah akan mempengaruhi suasana kelas, baik kebebasan yang dinikmati peserta didik dalam mengembangkan pikiran dan prestasinya ataupun sebaliknya bisa menjadi pengekangan dan keterbatasan tehadap pengembangan peserta didik dan sekolah itu sendiri. Penanaman nilai-nilai budaya sekolah dilaksanakan terutama saat pembelajaran di kelas dan akan berlanjut dalam pola kelakuan dan interaksi di luar kelas. Peserta didik pada saat pertama memasuki lingkungan sekolah akan mengalami proses sosialisasi dimana peserta didik memahami dan menjalankan budaya sekolah. Proses pembelajaran peserta didik dapat berjalan lancar karena ada budaya sekolah yang menentukan kelakuan dan tujuan yang diharapkan oleh guru, peserta didik dan para stakeholder. Nilai-nilai dan norma yang berlangsung di dalam sekolah juga harus memperhatikan budaya masyarakat terutama yang berlaku dalam keluarga peserta didik.

Pendidikan di sekolah pada hakikatnya merupakan usaha untuk mentransmisikan nilai kebudayaan, yang bertujuan mempertahankan, mengembangkan, dan mentransformasikan kebudayaan yang dimiliki masyarakat. Pengembangan nilai, kelakuan, rencana dan strategi sekolah secara terpola menghasilkan suatu budaya sekolah yang dianut bersama oleh pelaku-pelaku di dalamnya. Terdapat empat hal yang harus dibangun dan dibudayakan dalam rangka memupuk mentalitas berkompetisi dan berprestasi, sebagaimana ditekankan oleh Mendiknas. Pertama, bangun dan budayakan semangat kerja keras baik bagi guru maupun siswa karena tidak mungkin muncul sebuah prestasi hanya dengan bermalasmalasan. Kedua, bangun dan budayakan semangat berkompetisi yang dipadukan dengan semangat kooperasi. Ketiga, bangun dan budayakan kebiasaan berpikiran positif 
atau positive mind set, sebab bagi mereka yang selalu berpikiran positif, jangankan peluang atau harapan, masalah pun bisa mendatangkan peluang kebaikan. Keempat, bangun dan budayakan sikap sportif atau sportifitas.

Kebutuhan akan berprestasi atau need of achievement, sangatlah penting ditanamkan di lingkungan sekolah, sehingga para siswa tidak takut dan gentar menghadapi setiap kompetisi kapanpun, dimanapun dengan siapapun. Sementara itu, Sarlivanti (2010) menyebutkan, terdapat dua hal yang sangat berperan dalam upaya menciptakan iklim semangat berkompetisi dan prestasi pada siswa, yaitu, 1) Adanya sumber daya manusia yang berkualitas, terutama guru, karena guru memegang peranan kunci (sentral) dalam menguatkan (empowering) semangat kompetisi dan prestasi siswa-siswanya. Guru berprestasi akan menjadi inspirasi bagi murid-muridnya untuk berprestasi pula. 2) Budaya sekolah, nilai-nilai, sikap dan perilaku positif yang dikembangkan di lingkungan sekolah akan mendorong siswa untuk berprestasi dan siap berkompetisi secara sehat. Budaya sekolah (school culture) yang dikembangkan dan menjadi cara pikir, cara bersikap dan bertindak warga sekolahnya, terutama siswa merupakan kurikulum tersembunyi (hidden curriculum) bagi keseluruhan konsep dan program pendidikan yang dikembangkan. Oleh karena itu, sangat naïf dan merupakan paradox jika siswa ingin berprestasi tetapi tidak diciptakan iklim serta budaya sekolah yang apresiatif positif terhadap setiap prestasi warganya.

Kurikulum yang dipakai di SMA Muhammadiyah 10 Surabaya ini bernama "Talent Executive School." Kepala sekolah SMA Muhammadiyah 10 Surabaya menurut kepala sekolah alasan membuat sekolah ini yaitu karena pendidikan di Indonesia ini mewajibkan siswa untuk belajar banyak hal. Permasalahan yang ada di sekolah banyak sekali wali murid belum paham dengan konsep sekolah keberbakatan ini.karena orang tua murid cenderung ke nilai sedangkan kami menekankan pada produk / hasil yang mana siswa/I membuat bias membuat projek.

Pesertadidik sejak awal sudah diberikan kebebasan berpretasi dan berfikir melalui kegiatan-kegiatan di sekolah. Budaya yang ada di Sekolah yaitu penguatan religi dan penanganan terhadap siswa. Rapor yang diterima siswa berbeda dengan sekolah lain tidak hanya beruba angka tapi sebuah produk yang dikerjakan siswa bernama Rapor Vestifal yang sudah berjalan 2 tahun terakhir. Melalui konsep sekolah dan budaya sekolah serta pretasi yang sering di raih dan tetap aktif mengembangkan proses belajar mengajar menjadi daya tarik dalam peniliti untuk melakukan penelitian karena sekolah tersebut tidak terbatas memberikan inovasi walaupun sarana prasarana masih dalam pengembangan. Sekolah Sma Muhammadiyah 10 Surabaya ada yang melakukan pembelajaran di dalam Mall karena keterbatasan sarana dan prasarana. Tetap menerima siswa ABK dengan sarana yang masih terus dikembngkan.

SMA MUHAMMADIYAH 10 Surabaya merupakan sebuah sekolah baru yang kami jadikan jawaban atas permasalahan permasalahan aktual siswa. Siswa sebagai sentra utama pembelajaran membutuhkan fasilitas penting untuk mencapai cita - citanya. untuk itu sekolah ini hadir dalam mendukung terjadinya tujuan mulia tersebut. Visi dari Sebagai sarana proses belajar mengajar dalam meningkatkan prestasi, kompetensi spiritual, moral, dan intelektual. Misi Mengembangkan prestasi dan kompetensi dalam bidang IPTEK maupun IMTAQ.

SMA MUHAMMADIYAH 10 lahir dari sebuah ide untuk menciptakan generasi sekolah yang lebih siap menghadapi dunia perkuliahan dan dunia kerja, yang menyesuaikan dengan minat dan bakatnya. sekolah ini lebih mengedepankan pendidikan real life skill, dimana "penyentuhan" pada lingkunga kuliah atau kerja secara langsung.

Konsep pendidikan lebih didahulukan materi praaktek secara berkala, lalu secara perlahan didekatkan pada teori - teori ilmiah. hal ini merupakan kebalikan dari konsep pendidikan pada umunya. siswa yang belajar di sekolah ini akan lebih banyak belajar mengenai materi - materi yang akan dihadapi pada bangku kuliah dan kehidupan nyata. Sedangkan materi pelajaran sekolah yang tidak berhubungan tidak harrus ditekuni dengan intensif. 
Pemilihan studi tidak hanya didasarkan pada pilihan jurusan standar seperti IPA (Ilmu Pengetahuan Alam) atau IPS (Ilmu Pengetahuan Sosial) saja. Namun, lebih didasarkan pada minat melanjutkan studi selanjutnya (kuliah). Sehingga dari awal siswa akan memperoleh materi yang berkaitan dengan pilihanya tersebut.

Sekolah ini didesain untuk mengakomodasikan keinginan dan aspirasi siswa. Dimulai dari bakat dan minat mereka hingga pada pengembangan intelektualitasnya. Semua pernak - pernik dan tata pelaksanaan sekolah dijalankan oleh siswa, dan dipertanggung jawabkan konsekuen oleh mereka. Guru adalah fasilitator bagi jalanya kegiatan bersekolah. Diharapkan dengan itu, suasana pendidikan lebih semangat, fleksibel dan enjoyable bagi mereka.

Salah satu nilai karakter yang sangat menonjol dari sekolah SMAM 10 Surabaya adalah Religi. Pelaksanaan Religi secara resmi dan menyeluruh untuk para guru, peserta didik, pengurus Yayasan dan karyawan, yang selalu aktif dalam kegiatan kemuhamadiyahan wilayah walaupun perintisannya sudah dikembangkan pada tahun-tahun sebelumnya. Sikap Religi menjadi penting dalam membentuk kepribadian peserta didik karena tidak hanya cukup belajar mengolah pikir tetapi harus mampu olah hati, olah raga, dan olah rasa. Keseluruhan nilai-nilai dalam religi dijabarkan dalam empat nilai penting yaitu Mind, Heart, Body, Soul.

Empat nilai penting di dalamnya masih terdapat 10 nilai dasar (The Ten Fundamental Values) yaitu: Mind yang meliputi 3 nilai yakni Creativity, Analy-tical Thinking, dan Global Mindset; Heart yang meliputi 4 nilai yakni Respect, Responsibility, Caring, dan Trustworthiness; Body yang me-liputi 2 nilai yakni Fitness, dan Health serta Soul yang meliputi 1 nilai yakni The existence of God. Pemahaman dan aplikasi Ten Fun-damental Values yang baik diharapkan bisa memberdayakan Sumber Daya Manusia (SDM) Sekolah Muhammadiyah 10 Surabaya termasuk para peserta didiknya untuk bisa berpikir kreatif dalam penciptaan ide dan karya yang secara otomatis memacu untuk menganalisis segala sesuatu berdasarkan pada wawasan global yang bersifat positif dan konstruktif tanpa meninggalkan jati dirinya. Penanaman nilainilai penghargaan atau penghormatan terhadap diri sendiri dan orang lain, rasa tang-gung jawab, kepedulian terhadap lingkungan sekitar, yang secara sadar akan membentuk pribadi yang mempunyai integritas dan ber-jiwa patriotisme.

Sejarah pengembangan budaya berprestasi SMA Muhammadiyah 10 Surabaya dapat dianalisis menggunakan fungsi adaptasi dalam teori fungsional struktural. Perkembangan budaya berprestasi SMA Muhammadiyah 10 Surabaya yang bersifat dinamis menyesuaikan perkembangan masyarakat. Fungsi inilah yang dimaksudkan Parson dalam Johnson (130: 1990) sebagai penyesuaian dari sistem terhadap 'tuntutan kenyataan yang keras dan tidak dapat diu-bah' (inflexible) yang datang dari lingkungan. Penyesuaian lingkungan itu ada dua jenis yaitu sosial dan fisik. Penyesuaian lingkun-gan sosial SMA Karangturi dalam perkem-bangannya telah peka terhadap tuntutan orientasi masyarakat dalam pendidikan yai-tu yang berawal dari menomor satukan akademik dan nilai ujian dan beralih pola pikir yang mementingkan keseimbangan dalam kecerdasan akademik dan non akademik.Budaya sekolah di SMA Muhammadiyah 10 Surabaya meliputi empat poin yaitu: keseimbangan antara pembinaan akademik dan nonakademik; penanaman karakter yang bisa dilakukan pada pelajaran muatan lokal maupun masuk setiap pelajaran, dan pentingnya nilai religi.

Surabaya sehingga menjadikannya prestasi yang membanggakan dan akhirnya bisa mendukung masa depan yang lebih baik. Peran sekolah inilah yang begitu penting dalam memotivasi dari awal kepada peserta didik untuk berani percaya diri mengaktualisasikan segala potensi diri. Keberhasilan di masa depan bukan cuma ditentukan oleh prestasi akademik. Peserta didik juga diarahkan untuk bisa mengembangkan secara seimbang kemampuan akademik dan non akademik. Penanaman karakter sangat penting untuk menguatkan jiwa berbudaya dan na-sionalisme.

Kepala Sekolah dan para guru sangat penting dalam pengembangan budaya kepala sekolah berprestasi. Kepala Sekolah menjadi 
pihak penting karena kepala sekolah adalah yang mengelola budaya sekolah dan yang memiliki kemampuan manajerial untuk pengelolaan kegiatan sekolah (Hidayat, 2005). Sementara itu guru merupakan pihak yang penting karena langsung berhadapan dengan peserta didik. Tugas pengembangan budaya sekolah berprestasi terutama perencanaan dan evaluasi tidak bisa menjadi tanggung jawab pimpinan sekolah SMA Muhammadiyah 10 Surabaya yang bersifat perintah atau TopBottom tetapi menjadi tugas bersama dan adakalanya bersifat Bottom Up.

Guru juga bisa mengusulkan maupun ikut mengevaluasi kegiatan maupun program sekolah yang berkaitan dengan budaya sekolah berprestasi. Koordinasi dan kolaborasi bersama inilah menjadi faktor penting keserasian pandangan dan langkah untuk mencapai tujuan sekolah yang diharapkan.Penanaman nilai dan etos budaya sekolah berprestasi SMA Muhammadiyah 10 Surabaya dilakukan melalui proses pembelajaran di kelas, evaluasi belajar, proses pembelajaran di luar kelas, ekstrakurikuler, pemberian penghargaan prestasi, penanaman melalui simbol-simbol motivasi dan afirmatif, membangun kecintaan terhadap almamater, membangun keteladanan guru, membagun kerjasama dengan orang tua peserta didik, SMA Muhammadiyah 10 Surabaya memiliki faktor pendorong sekaligus penghambat. Salah satu faktor pendorong adalah sumber belajar yang berupa fasilitas yang tersedia di SMA Muhammadiyah 10 Surabaya yang bisa membantu proses pembelajaran di SMA Muhammadiyah 10 Surabaya yang lebih mengutamakan keaktifan dan pengalaman peserta didik. Faktor pendorong lain adalah pembelajaran di SMA Muhammadiyah 10 Surabaya yang selalu mendukung untuk peserta didik untuk bisa mengembangkan materi pelajaran lebih luas lagi, menemukan manfaat dan bisa berprestasi di dalam dan di luar sekolah.

Ekstrakurikuler di SMA Muhammadiyah 10 Surabaya juga tidak hanya sebatas pengembangan bakat maupun hobi tetapi juga untuk mempersiapkan keikutsertaan dalam lomba maupun kompetisi sehingga tujuannya adalah prestasi.Hubungan yang baik antara orangtua peserta didik, sekolah dan yayasan dalam bentuk perhatian terhadap prestasi SMA Muhammadiyah 10 Surabaya juga menjadi faktor pendorong penanaman budaya berprestasi. Orangtua peserta didik selalu memantau prestasi anaknya, ketersediaan fasilitas belajar, dan proses pembelajaran yang berlangsung di sekolah, dan memberikan masukan untuk kemajuan.

Selain faktor pendorong yang telah disampaikan, terdapat pula beberapa faktor yang menghambat penanaman budaya berprestasi di SMA Muhammadiyah 10 Surabaya. Salah satunya adalah keterbatasan dalam memfasilitasi bakat nonakademik peserta didik di bidang olahraga tertentu, karena sempitnya lahan sekolah Karangturi untuk kegiatan olahraga. Selama ini SMAM $X$ memang terkenal sangat berprestasi dalam olahraga hockey, namun untuk olahraga lainnya nampaknya sekolah ini kesulitan dalam pengembangan karena keterbatasan lahan. Hambatan lain yang dialami adalah sering terjadinya miskomunikasi orangtua peserta didik terutama kelas $\mathrm{X}$, yang tampak pada seringnya mereka memprotes sekolah mengenai banyaknya penugasan yang diberikan guru kepada peserta didik. Namun sekolah menganggap penugasan tersebut sangat penting untuk tetap dilakukan karena mem-beri keuntungan pada siswa saat menjalani proses pembelajaran maupun selepas SMA.

Bentuk proses dalam prestasi adalah kinerja sekolah yang memuat program sekolah, inovasi yang dikembangkan, kerja-sama instansi maupun etos dalam upaya mendukung budaya berprestasi. Visi misi SMA Muhammadiyah 10 Surabaya yang dilengkapi dengan falsafah pembelajaran dan karakter Patriot telah memberikan dasar yang kuat sekaligus arahan yang jelas untuk program-progam sekolah yang akan dikembangkan. Nilai-nilai semangat wirausaha berwawasan global telah dikembangkan dengan nilai-nilai dan etos kerja keras, disiplin, persaingan yang sehat, kepemimpinan, dan kepedulian. Inovasi pembelajaran yang dikembangkan di dalam kelas, luar kelas (clinical dan tim olimpiade) maupun ekstrakurikuler menjadi strategi untuk selalu mengikuti perkembangan pendi-dikan. 
Kerjasama SMA Muhammadiyah 10 Surabaya dengan beberapa sister school yang ada di luar negeri menjadi bukti pengembangan sekolah ke arah standar internasional. Profesionalisme yang tinggi dan hubungan antara guru, kepala sekolah dan yayasan yang dekat diwu-judkan dalam rapat bersama dalam hal perkembangan inovasi pembelajaran, evaluasi prestasi sekolah, maupun bentuk keakraban (sharing, rekreasi bersama atau outbond). Dalam hal output, prestasi SMA Muhammadiyah 10 Surabaya berwujud dalam dua bentuk yaitu prestasi akademik dan prestasi non akademik. Prestasi SMA Muhammadiyah 10 Surabaya menunjukkan keseimbangan antara prestasi akademik dan prestasi non akademik. Prestasi yang diraih peserta didik SMA Muhammadiyah 10 Surabaya ini merupakan hasil budaya sekolah berprestasi yang ditanamkan mulai pertama kali masuk dan selama proses pembelajaran. Prestasi peserta didik SMA Muhammadiyah 10 Surabaya juga didukung oleh guru-guru dan pembina ekstrakurikuler yang banyak berkualitas dan ahli dalam bidangnya serta keaktifan membina peserta didik untuk mengikuti kompetisi.

Alumni SMA Muhammadiyah 10 Surabaya tidak hanya memiliki kecerdasan pengetahuan tetapi juga cerdas secara emosional spiritual, berjiwa wirausaha, pekerja keras, tahan terhadap tekanan dan mempunyai banyak hubungan usaha. Budaya berprestasi ini melekat sampai dunia kerja dan di kehidupan masyarakat menjadi pengusaha sekaligus pemimpin yang berkarakter dan berjiwa sosial. Pengembangan budaya sekolah ber-prestasi memang tidak hanya dilihat dalam prosesnya, kelulusan maupun langsung terlihat hasilnya tetapi juga prestasi yang paling penting adalah karakter dalam jangka waktu yang lama. Output prestasi yang dianggap berharga adalah kesan yang baik oleh para alumni sehingga merasakan manfaatnya di masa depan.

\section{KESIMPULAN}

Budaya sekolah berprestasi di SMA Muhammadiyah 10 Surabaya dapat berjalan dengan baik karena seluruh tenaga pendidikan dan kependidikan tidak hanya mengikuti kode etik yang sudah ada. Tetapi guru juga harus memiliki rasa tanggungjawab dan amanah terhadap apa yang sudah diberikan serta terjalanin kedekatan yang baik antar siswa dan guru dengan tetap menekankan nilai-nilai religi yang ada.

Adanya kurikulum sendiri yang dipakai di dalam sekolah untuk mengembangkan etos berprestasi terhadap siswa, dengan memberikan fasilitas sesuai dengan minat dan bakat siswa. Di sekolah juga menggunakan rapor yang berbeda dengan sekolah lain yaitu rapor vertifal yang sudah berjalan sejak 2 tahun terakhir. Tetapi SMA Muhammadiyah tetap selalu melaporkan kegiatan dan mengikuti kurikulum yang dibuat pemerintah hanya saja saat pelaksanaan sekolah melakukan modifikasi untuk mengembangkan nilai dan etos berpretasi untuk peserta didik dan guru dalam proses pengembangan pembelajaran.

\section{UCAPAN TERIMAKASIH}

Ucapan terimakasih ditujukan kepada SMA Muhammadiyah 10 Surabaya serta Universitas Negeri Surabaya.

\section{DAFTAR PUSTAKA}

Amir, Y.H. 2005. Kepemimpinan Kepala Sekolah yang Berorientasi Penguatan Budaya Organisasi dan Perbaikan Mutu Pendidikan di Sekolah Swasta Berciri Khas Islam: Model Konseptual Berdasarkan Kasus SMA Al-Irsyad Tegal. Mimbar Pendidikan No. 2/XXIV/2005

Aritonang, K.T. 2008. Minat dan Motivasi dalam Meningkatkan Hasil Belajar Siswa. Jurnal Pendidikan Penabur. 7(10)

Bukhori, I. dan Anita, N. 2009. Pengaruh Kultur Sekolah Terhadap Motivasi Belajar Siswa Melalui Kinerja Guru. Jurnal Penelitian Kependidikan. 19(2): 60-80

Garliah, L. dan Nasution, F.K. 2005. Peran Pola Asuh Orang Tua dalam Motivasi Berprestasi. Jurnal Psikologia. 1

Isjoni. 2006. Pendidikan sebagai Investasi Masa Depan. Jakarta: Yayasan Obor Indonesia

Johnson, D.P. 1990. Teori Sosiologi Klasik dan Modern.Jakarta: Gramedia

Moleong, L. 2002. Metodologi Penelitian Kualitatif. Bandung: Remaja Rosda Karya 
Permenag ke -1 penulisan artikel yang diselenggarakan Kemendiknas tahun 2010

Sugiyono. 2008. Metode Penelitian Pendidikan: Pendekatan Kuantitatif, Kualitatif, dan R\&D. Bandung; Alfabeta.

Yuliono, Agus. 2011. Pengembangan Budaya Sekolah Berprestasi: Studi Tentang Penanaman Nilai Dan Etos Berprestasi Di Sma Karangturi 